\title{
do caderno de anotacões dos editores (prelúdio)
}

(Escrito a dez mãos num arquivo compartilhado).

Dezembro de 2020 ... Nos primeiros meses de 1959, Lúcio Cardoso lançou a Crônica da casa assassinada, seu último romance finalizado em vida, seu retorno ao gênero desde Dias perdidos (1943) e obra máxima na sua longa carreira literária. Publicado pela editora José Olympio, o romance imediatamente tomou as páginas da imprensa, sendo motivo de querelas entre intelectuais e escritores da época. Lúcio, que havia estreado na literatura no conturbado período de acirramento político, estético e ideológico dos anos 1930, mais uma vez viu uma obra sua marcada pelo sinal da polêmica. Desta vez o estopim foi uma resenha do crítico recifense Olívio Montenegro, que, escandalizado pelas passagens mais grotescas e pela temática do incesto, classificou a Crônica como "um romance imoral" e "um fato mais escatológico do que literário".

A primeira réplica ao ataque veio numa entrevista ao crítico José Condé, que assinava a coluna "Escritores e Livros" do Correio da Manhã. Adotando um tom jocoso, Lúcio Cardoso ironizou o moralismo de Montenegro:

\footnotetext{
Que idade terá atualmente o meu prezado Olívio, para considerar assim tão "imoral" relações normais entre um homem e uma mulher? Que coisa melancólica: é evidente que estamos muito longe da época em que ele louvava sem restrições as páginas mais cruas do romance Banguê, de José Lins do Rego. [...] Isto me surpreendeu e me divertiu ao mesmo tempo: meu velho amigo Olívio Montenegro deve estar implicando comigo, pois, se me acusa de descrever um incesto para efeito de literatura, nem sequer chegou a terminar o livro - porque incesto não há...
}

Nesse meio-tempo, Walmir Ayala, escritor e crítico literário, saiu em defesa de seu amigo Lúcio nas páginas dos jornais, mas não o fez sozinho: convocou uma dezena de escritores, colhendo de cada um deles um posicionamento sobre a leitura moralizante de Olívio. Octávio de Faria, Manuel Bandeira, Adonias Filho, Eneida e Armindo Pereira, Lêdo Ivo, Assis Brasil, Aníbal Machado, Paschoal Carlos Magno, Dinah Silveira de Queiroz - cada um deles recusou a condenação da Crônica, defendendo a autonomia da obra de arte diante de temas considerados ética ou moralmente problemáticos. Manuel Bandeira sintetiza: 


\title{
opiniães
}

\author{
Por princípio religioso, pode-se exigir uma moralidade num \\ romance, [nunca] por princípio artístico. Um romance cheio das \\ piores cenas pode vir de encontro a ideias políticas e religiosas e \\ ser magnificamente escrito. Em se tratando de romance, isto é o \\ que interessa, e só isto conta.
}

Em que pese o calor de sua primeira recepção, os anos seguintes arrefeceram o debate em torno do tema do incesto na Crônica da casa assassinada. $\mathrm{Na}$ verdade, a questão se inverteu: o que se questiona agora é por qual motivo a relação incestuosa entre Nina e André não ter sido levada até às últimas consequências. Teria Lúcio Cardoso recuado diante do tabu? Qualquer que tenha sido o motivo, o fato é que, nos meses seguintes ao lançamento, a Crônica agradou a crítica literária, que passou a destacar seu apuro estético e sua estrutura complexa.

Nos anos 1970, a circulação da obra foi ampliada a partir da adaptação cinematográfica realizada por Paulo César Saraceni. A casa assassinada contou com grande elenco, trilha sonora de Tom Jobim e arrebatou prêmios em diversos festivais. Na década seguinte, novo marco na leitura do romance, agora vindo do pesquisador franco-ítalo-brasileiro Mario Carelli. Sua tese de doutorado, defendida na Sorbonne, foi traduzida para o português por Júlio Castañon Guimarães e publicada no Brasil com o título Corcel de fogo: vida e obra de Lúcio Cardoso (19121968), em 1988. O livro, que trafega entre a biografia e a análise literária, possui o mérito de identificar com precisão as linhas de força da produção cardosiana, servindo de excelente ponto de partida para quem deseja se aprofundar nos estudos da obra de Lúcio. Dotado de uma visão totalizante, que transita entre a prosa de ficção (romances, contos, novelas e crônicas) e as demais expressões artísticas praticadas pelo polígrafo Lúcio Cardoso (como a poesia, a dramaturgia, o cinema e a pintura), Mario Carelli conseguiu mapear os fios subterrâneos que interligam as diversas produções sem enredar seus leitores nos riscos de uma leitura unívoca. $\mathrm{O}$ pesquisador também foi o responsável pela edição crítica do romance, publicada na Coleção Archivos, da Unesco; além de ter traduzido para o francês a novela Inácio e a própria Crônica da casa assassinada.

A partir dos trabalhos de Mario Carelli, a crítica universitária começou a se interessar mais por Lúcio Cardoso e pela Crônica (ainda hoje, a obra mais estudada do escritor). As veredas da interpretação experimentadas nos últimos quarenta anos são amplas e atestam a riqueza polissêmica do romance. Elas passam pelos estudos sobre as vozes narrativas e a questão da polifonia (em Mario Carelli, José Américo Miranda de Barros); pela investigação da forma do romance e do seu 
lugar na historiografia literária (Alfredo Bosi, Luís Bueno, Teresa de Almeida, Cássia dos Santos, Marília Rothier Cardoso); pela questão do feminino, do trágico, do gótico e da investigação psicanalítica (Elizabeth Cardoso, Ruth Silviano Brandão, Maria Teresinha Martins, Beatriz Damasceno); até as novas leituras advindas dos Estudos Culturais, a partir da relação entre as personagens Nina e Ana, e a esfinge que é Timóteo. Para além da literatura, Crônica da casa assassinada também ressoou em outras expressões artísticas, como no cinema de Paulo César Saraceni e Luiz Carlos Lacerda, no teatro de Dib Carneiro Neto, nas artes plásticas (como os trabalhos de Adriana Varejão) e na música de Tom Jobim.

A virada dos anos 2000 inaugurou uma nova fase nas edições da Crônica da casa assassinada e nas demais obras de Lúcio Cardoso. Em 1999, a editora Civilização Brasileira lançou uma edição comemorativa dos quarenta anos do romance; dez anos depois, publicou outra edição, de cinquenta anos. Diversos empreendimentos editoriais de fôlego foram realizados nas duas décadas seguintes, permitindo ao leitor adquirir obras que estavam fora de catálogo há muitos anos, além de entrar em contato com um material que durante muito tempo permaneceu depositado em arquivos ou dispersos. Diários, Poesia completa, Teatro reunido, Contos da ilha e do continente, reedição de todos os romances publicados em vida, reedição das traduções feitas por Lúcio (Orgulho e preconceito, Drácula e o livro $O$ vento da noite, com poemas de Emily Brontë), todas essas obras permitem vislumbrar uma vida dedicada à literatura, um escritor que trafega sem medo por diversas expressões artísticas.

Nos últimos anos, outro movimento de abertura se iniciou ao redor da Crônica da casa assassinada. Em 2016, a Open Letter Books publicou Chronicle of the Murdered House, tradução para o inglês realizada por Margaret Jull Costa e Robin Patterson. O trabalho foi agraciado com o prêmio de Melhor Tradução no Book Awards de 2017. Em 2018, os cinquenta anos da morte de Lúcio Cardoso foram marcados pela realização da jornada Lúcio Cardoso: 50 anos depois, organizada pelo professor Leandro Garcia Rodrigues na Universidade Federal de Minas Gerais, resultando no livro de ensaios homônimo (Edições Relicário, 2020). Naquele mesmo ano, a Crônica ganhou uma edição portuguesa, publicada pela editora Compasso dos Ventos. Em 2019, foi a vez do Colóquio Elegia Mineira: 60 anos da Crônica da casa assassinada, que reuniu mais de trinta apresentações em dois dias de evento: no dia 8 de novembro de 2019, em Niterói, na Universidade Federal Fluminense (UFF), e em 22 de novembro no campus da capital da Universidade de São Paulo (USP). Em 2020, apesar da pandemia do novo coronavírus, recebemos a notícia de que a Crônica da casa assassinada terá a 


\section{opiniães}

Companhia das Letras como nova casa editorial, e que uma nova tradução da obra, agora para o holandês, está em fase de preparação.

... Parte dos trabalhos desta edição foi apresentada primeiramente no Colóquio Elegia Mineira: 60 anos da Crônica da casa assassinada. Integrando mais de trinta apresentações, a efeméride da publicação da obra-prima de Lúcio Cardoso serviu como oportunidade para reunir pelo menos três gerações de cardosianos (ou lucistas, a depender do grupo) num generoso espaço de interlocução. A leitura do dossiê temático permitirá ao leitor conhecer as grandes linhas interpretativas não apenas da Crônica, mas também de outras produções do escritor mineiro.

O dossiê temático se abre com uma visita ao acervo de Ésio Macedo Ribeiro, que apresenta aos leitores as capas de todas as edições já publicadas da Crônica da casa assassinada até o momento (incluindo uma edição portuguesa, uma norte-americana e duas francesas). Completam a bibliografia ilustrada o cartaz do filme $A$ casa assassinada, dirigido por Paulo César Saraceni, e os programas da adaptação teatral realizada por Dib Carneiro Neto e dirigida por Gabriel Villela. Em seguida, duas dezenas de pesquisadores se debruçam sobre o romance de Lúcio Cardoso. Os artigos de Erica Gaião e Leonardo Ramos Botelho Gomes identificam os temas e os procedimentos advindos da estética gótica que influenciaram a produção ficcional e dramatúrgica de Lúcio Cardoso. Em seguida, cinco artigos investigam as personagens femininas: Elizabeth Cardoso identifica a feminilidade como um mecanismo que desencadeia a desagregação familiar; Romildo Biar Monteiro se debruça sobre a questão do Mal no romance e observa como as figuras femininas frequentemente se rebelam contra os discursos punitivos e castradores que as cercam; Livia Azevedo Lima analisa o contraste entre palavra e imagem no filme $A$ casa assassinada, de Paulo César Saraceni, e aproxima Nina e Ana, duas mulheres que se complementam na rivalidade; e Érica Ignácio da Costa analisa o filme inacabado dirigido por Lúcio Cardoso, A mulher de longe, concentrando sua interpretação nas figuras das mulheres forasteiras.

O conjunto seguinte de artigos é dedicado à investigação dos aspectos formais da Crônica da casa assassinada, um tema que ainda hoje continua deslumbrando os leitores do romance e desafiando a crítica literária. O intrincado jogo de vozes textuais, de embaralhamento temporal e de montagem da complexa arquitetura narrativa são investigados por Sandro Adriano da Silva, Frederico van Erven Cabala e Eduardo Marinho da Silva. Leandro Garcia, por sua vez, analisa como a dimensão epistolar interfere ativamente na economia do romance. Já 
Beatriz Damasceno, partindo da leitura dos Diários de Lúcio Cardoso, retoma as várias etapas do processo de criação de $O$ viajante, romance que permaneceu incompleto e que antecedeu a escritura da Crônica da casa assassinada (apesar de os eventos ali narrados serem posteriores ao enredo do romance de 1959).

Os artigos seguintes se debruçam sobre a herança colonial e as transformações políticas, históricas e sociais que situam a família Meneses como representantes da decadência da oligarquia rural mineira na crise do final do Brasil Império e na passagem da República Velha ao Estado Novo. É o caso das leituras de Ana Maria Amorim Correia, que estuda a figura do Barão, obsessão do mais Meneses dos Meneses, Demétrio; de Rafael Batista de Sousa, que vislumbra no retrato da ruína familiar a consciência do atraso; de Leo Stephen Merlin Temple, que aproxima as dimensões espirituais e materiais para investigar o esfacelamento da casa-grande; e de Victor Hugo Adler Pereira, que evidencia a crise do patriarcado rural brasileiro a partir de uma leitura comparada entre Lúcio Cardoso, Nelson Rodrigues e José Lins do Rêgo.

A linguagem exuberante da prosa cardosiana é investigada no artigo de Ernani Terra, que analisa o discurso da interdição no tecido linguístico da Crônica. Diogo Andrade de Lima investiga a noção nietzschiana de transvaloração, aproximando a figura de Timóteo e a do próprio Lúcio Cardoso, num movimento de resistência e enfrentamento à tradição mineira. Já o artigo de Bruna Freitas Figueiredo faz uma instigante análise comparativa entre a Crônica da casa assassinada e as obras da artista plástica Adriana Varejão, tendo como elemento condutor a estética barroca. A seção de artigos é encerrada, numa sucessão acronológica, com uma análise de Valéria Lamego, que mostra os pontos de contato entre a coluna "O crime do dia", mantida por Lúcio Cardoso entre as décadas de 1930 e 1950 e a Crônica da casa assassinada.

... Após o dossiê temático, foi criada uma seção especial cuja arquitetura encena um jogo de muitas vozes, tal qual a própria Crônica da casa assassinada. Convidamos 21 leitores para nos fazer um relato (seriam esses registros memórias, anotações de diário, confissões?) contando suas experiências de leitura da obra e como ela influenciou seus trabalhos posteriores, seus estudos e suas visões de mundo. A lista é heterogênea e reúne escritores, críticos literários, cineastas, roteiristas, dramaturgos, professores, pesquisadores, estudantes e leitores. Os relatos que nos chegaram são emocionantes e destacam uma experiência 


\section{opiniães}

arrebatadora, ressaltando os vincos profundos que a família Meneses deixou em suas memórias.

A seção se abre com o belo texto de Luís Bueno, que mistura a seriedade do trabalho do crítico com a memória afetiva do leitor para relembrar trinta anos de leitura da Crônica da casa assassinada. Em seguida, o escritor Milton Hatoum rememora suas leituras da Crônica e evidencia as reverberações do romance em sua obra. André Seffrin, autor de um incontornável prefácio a uma das edições do romance, retorna agora, vinte anos depois, para um balanço de leitura, mobilizando os retalhos de convivência de Lúcio (ou Nonô) com outros nomes da literatura que lhe eram próximos, como Octávio de Faria e Walmir Ayala. Amara Moira, travesti, escritora e pesquisadora, clama por leituras do livro que sejam monstruosas à maneira da desconcertante definição de liberdade dada por Timóteo. Júlio Castañon Guimarães partilha suas lembranças da preparação da edição crítica do romance, que convivem agora com fragmentos da adaptação cinematográfica de Paulo César Saraceni. Xikito Affonso Ferreira relembra um Lúcio caminhando entre a fé e a transgressão, dilema definidor de seus romances e de seu comportamento de "arcanjo rebelde". Newton Vieira, curvelano como Lúcio Cardoso, nos confessa ter as estruturas íntimas sacudidas pela leitura do romance, restando a difícil tarefa de situar na ampulheta do tempo o universo da Crônica.

Não podíamos deixar escapar os transbordamentos da Crônica para outras artes. O roteirista George Moura nos convida a conhecer o laboratório de sua criação, compartilhando com os leitores seu processo de realização de uma nova adaptação do romance para os cinemas. De Luiz Carlos Lacerda, o Bigode, a memória afetiva de um cineasta cuja obra mantém um diálogo profundo com os trabalhos de Lúcio. O cineasta Ney Costa Santos compartilha nostálgicas imaginações a respeito dos possíveis percursos de Lúcio Cardoso por Ipanema imaginações sonoras, sempre acompanhadas da trilha feita por Tom Jobim à adaptação de Paulo César Saraceni. O dramaturgo Dib Carneiro Neto conta como seu processo de reescrita do romance para os palcos tentou evitar a perda de uma característica vital do texto: seu caráter epistolar.

Tomam parte, ainda nessa seção de depoimentos, professores, pesquisadores e leitores da Crônica. Denilson Lopes se vê de novo às voltas com a obra de Lúcio Cardoso, agora curioso por enxergar uma outra senda do modernismo na ficção brasileira. Júlio Machado, professor e escritor, fala da leitura da Crônica como um retorno ao seu labirinto pessoal, arraigado em uma Minas Gerais feita de ficção e de história. Já o professor Marcos Antonio de Moraes apresenta fragmentos de comentários seus realizados em diversas bancas de pósgraduação que tiveram a Crônica e a obra do Lúcio como tema principal. Leandro 
Garcia Rodrigues relata o abalo sentido pela leitura da Crônica em sua vida pessoal, de origens intensamente católicas: “Como ler Timóteo?" é a pergunta espantada que reverbera em seu íntimo. Simone Rossinetti Rufinoni percorre as forças antagônicas que caracterizam a vertigem do romance, os embates entre liberdade e opressão a que estão sujeitas as personagens, embates capazes de minar os pilares da casa-país. A psicanalista Nádia Degrazia revela sua leitura engajada, tomando partido de determinados personagens e submergindo nas verdades parciais dos Meneses. A estudante de Letras Thais Gomes rememora as sensações emanadas pelo livro, pelas personagens e pelos dias tipicamente quentes do interior de Minas. Alexandre Siqueira, engenheiro aposentado e leitor ativo, completa essa rodada de palavras, identificando nas paredes gélidas da Chácara um mal que talvez assombre a todos nós, leitores - a doença Crônica: não incurável, pois ramos podem irromper dos moldes do canteiro de violetas.

Por fim, contamos com um depoimento de Andrea Vilela, sobrinha-neta de Lúcio Cardoso e professora da Escola de Belas Artes da UFMG, que vislumbra a Crônica como uma metáfora da obra do autor, um mosaico em que peças brilhantes, aparentemente autônomas, podem ser vistas em uma coreografia conjunta. Fecham a seção dois textos essenciais, neste momento em que esse romance de Lúcio Cardoso ganha novas possibilidades de leitura mundo afora. Os tradutores da edição norte-americana da Crônica da casa assassinada, Margaret Jull Costa e Robin Patterson, e o tradutor Harrie Lemmens, que prepara agora uma tradução do romance para o holandês, dão seus depoimentos a respeito do translado da Chácara, tão arraigadamente mineira, para outros campos linguísticos, que talvez lhe sirvam muito bem. "Não há equivalente no cânone de língua inglesa - ou talvez em nenhum outro", concluem os tradutores Margaret Jull Costa e Robin Patterson.

Os depoimentos são acompanhados de um rico material iconográfico, alguns ainda inéditos, outros mais raros, que só o leitor especializado normalmente tem acesso. Há fotografias de Lúcio (desde sua juventude nos anos 1930, até os anos 1960); desenhos e pinturas - estas últimas cultivadas principalmente após o seu derrame, em 1962, que lhe paralisou o lado direito do corpo e suprimiu a sua fala; e obras que foram inspiradas na Crônica (caso do tríptico Elegia mineira, de Adriana Varejão). Depoimentos e imagens são alinhavados com trechos da Crônica, espalhados aqui e ali para que o leitor relembre algumas passagens (e para atiçar a vontade de quem ainda não adentrou a Chácara dos Meneses). 


\section{opiniães}

... Na seção de Tema Livre, contamos com quatro artigos que nos fornecem pistas provocadoras sobre diferentes tópicos. Cláudia Ayumi Enabe investiga o romance de Raduan Nassar a partir da chave das disputas ideológicas advindas da divergência dos discursos familiares. Thamiris Yuri Silveira Pellizzari traz ao debate temas como a dependência e a tradição para pensar as relações entre crítica literária e sociedade, principalmente a partir das ideias de Eneida Maria de Souza e Antonio Candido. Jean Bruno Carvalho resgata uma autora pioneira na dramaturgia nacional e realiza uma análise comparativa com o teatro de José de Alencar, a fim de identificar as distintas posições desses dramaturgos. O último texto da seção, de Carla Casarin Leonardi, se debruça sobre um conto de Clarice Lispector e perscruta a imagem da mulher idosa e a carga de melancolia a ela atribuída pelos elementos manifestos e latentes no texto.

A seção Criação Literária traz crônica de Bruno Rosa, contos de Julia de Almeida Baranski, Luci Collin e Monalisa Bomfim, e poemas de Frederico Klumb, Júlio Machado, Maílson Furtado Vianna, Valeska Torres. Na seção Resenha, Ana Resende analisa o livro O corpo descoberto: contos eróticos brasileiros (1852-1922), de Eliane Robert Moraes. Por fim, a Opiniães se encerra com a seção Tradução poética, em que o tradutor Filipe de Brito nos apresenta seis poemas do poeta simbolista russo Fiódor Sologúb, vertidos pela primeira vez do russo para o português.

As seções de tema livre, criação literária, resenha e tradução contam ainda, entre suas páginas, com alguns trabalhos gráficos realizados e gentilmente cedidos pela artista visual Sayuri Kashimura, de Curitiba, e pelo ilustrador Camilo Martins, do Rio de Janeiro.

... Lúcio Cardoso é um escritor que desperta ira ou paixão, a depender de seu leitor, e a Crônica, apesar de ter recebido pelo menos uma dezena de edições nestes sessenta anos de publicação, ainda está longe de ser conhecida e reconhecida pelo grande público. Nesse sentido, esperamos que esta edição da Opiniães, preparada com muita dedicação no trágico ano de 2020, atraia leitores, instigue a realização de pesquisas, permita (re)descobrir este escritor sempre ansioso por novos leitores.

Gestada ao longo de dois anos, esta edição não teria sido possível sem o apoio de diversos colaboradores, a quem agradecemos profundamente. À comissão editorial da Opiniães e ao nosso amplo corpo de pareceristas, que com seriedade colaborou com os editores na seleção dos textos. Aos pesquisadores que participaram do Colóquio Elegia Mineira (em São Paulo e/ ou em Niterói). 
Agradecemos à Simone Rossinetti Rufinoni, professora e coordenadora do Programa de Pós-Graduação em Literatura Brasileira da USP e aos professores Silvio Renato Jorge e André Dias, coordenador e vice coordenador do Programa de Pós-Graduação em Estudos de Literatura da UFF, pelo apoio na realização do evento itinerante. Aos escritores, pesquisadores e leitores que nos encaminharam seus depoimentos e partilharam suas paixões pela literatura, por Lúcio Cardoso e pela Crônica. Um agradecimento especial a Ésio Macedo Ribeiro, Andrea Vilela, Luiz Carlos Lacerda, Valéria Lamego e André Seffrin pelo envio das imagens e a Rafael Cardoso pela autorização para reproduzi-las na revista.

Cada vez mais se reconhece na Crônica uma obra capaz de sintetizar questões de ordem externa e interna, objetiva e subjetiva. Mikhail Bakhtin afirma que "as obras dissolvem fronteiras da sua época, vivem nos séculos, isto é, no grande tempo". Sessenta (e um!) anos depois da primeira publicação, é à luz dessa leitura que podemos situar este grande romance de Lúcio Cardoso.

Editoras e Editores da Opiniães n. 17 Ana Maria Amorim Correia, Eduardo Marinho da Silva, Érica Ignácio da Costa, Frederico van Erven Cabala, Livia Azevedo Lima 